\title{
Reactivity of sterically hindered diarylbenzhydryl carbocations - competing trapping by nucleophiles and elimination
}

\author{
Anthony F. Hegarty* and Valerie E.Wolfe \\ School of Chemistry and Chemical Biology, University College Dublin, Dublin 4, Ireland. \\ f.hegarty@ucd.ie
}

\begin{abstract}
Dedicated to Nouria Al-Awadi on her $55^{\text {th }}$ birthday and her appointment as Vice-President for Academic Affairs at the University of Kuwait
\end{abstract}

\begin{abstract}
The bis-(pentamethylphenyl)carbocation 11c, can be formed from the corresponding alcohol 10c in concentrated sulfuric acid or from the sec-alkyl chloride 12c in ionizing solvents. The $\mathrm{pK}_{\mathrm{R}}$ value for the equilibrium between the cation and the alcohol was measured as -4.80 , while the $\mathrm{p} K_{\mathrm{a}}$ of the carbocation 11c was estimated as -6.04. Elimination (to give the xylylene 3) competes with trapping of this carbocation in a ratio of 22:1 in aqueous dioxanee. Trapping of the carbocation by $\mathrm{N}_{3}^{-}, \mathrm{H}_{2} \mathrm{O}$ and alcohols show that this carbocation is selective, but particularly so for reactions with secondary alcohols. In each case comparison is made with the trapping of bis-(mesityl)carbocation 11b and the bis-(o-tolyl)carbocation 11a, neither of which undergoes competing elimination in the reaction with water.
\end{abstract}

Keywords: Carbocation reactivity, buttressing effects, $\mathrm{p} K_{\mathrm{R}}$ values, common ion effect, carbocation $\mathrm{p} K_{\mathrm{a}}$

\section{Introduction}

We have previously shown that the protonation of an $s p^{2}$ carbon centre can be significantly slowed by the presence of two highly substituted aryl groups. For example, two pentamethylphenyl groups at the protonation site slow the rate of protonation of the carbon in $\mathbf{1}$ by a factor of $10^{5}$, which permits the observation of the enol of the acid 2 , in solution. ${ }^{1}$

We now report on the synthesis of a number of carbocation precursors which carry similar large groups in order to determine whether these effects also operate in the formation of the carbocation from the corresponding chlorides and in the subsequent reactions of the carbocations. We have also noted that, in the most sterically hindered cations which we have studied, elimination to form 5,6-dimethylenecyclohexa-1,3-diene (a "xylylene") $\mathbf{3}$ also occurs in a competing reaction. 
Other reports on the effect of added $o$-methyl groups on the rates and product distributions of cumyl derivatives have shown that the tert-carbocations can undergo nucleophilic trapping by the solvent or added nucleophiles in competition with deprotonation of the $\alpha$-methyl group to form the corresponding $\alpha$-methylstyrenes. For example the incorporation of two o-methyl groups does slow nucleophilic attack on the carbocation (70-fold) while increasing the rate of deprotonation to the solvent 60 -fold. ${ }^{2,3}$

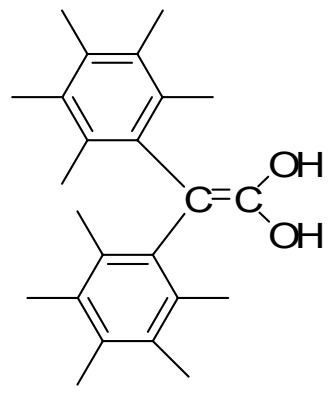

1

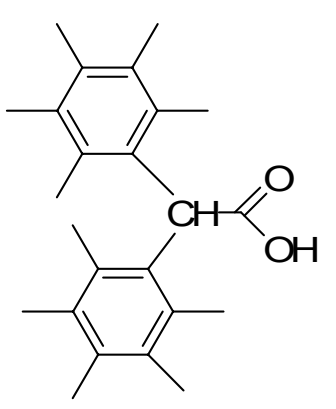

2

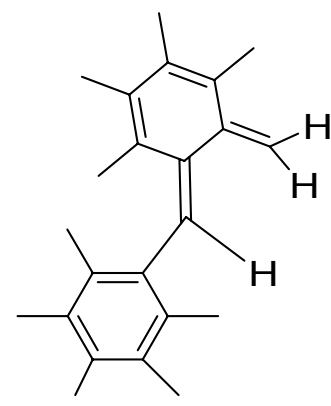

3

\section{Results and Discussion}

Synthesis of substrates. The precursors formed in the present study were synthesised by the sequence outlined in Scheme 1. For example, pentamethylbenzoic acid $\mathbf{5}$ was formed from the reaction of oxalyl chloride under Friedel-Crafts conditions with pentamethylbenzene 4. This was converted into the corresponding chloride $\mathbf{6}$ and then reacted with the Grignard reagent formed from pentamethylbromobenzene to give bis(2,3,4,5,6-pentamethylphenyl)methanone 7, which was then reduced to the corresponding alcohol 8. This was then converted to the carbocation precursor, chlorobis(2,3,4,5,6-pentamethylphenyl)methane, 9. 
<smiles>Cc1c(C)c(C)c(C(=O)OCc2c(C)c(C)c(C(=O)OCc3c(C)c(C)c(C(=O)Cl)c(C)c3C)c(C)c2C(=O)O)c(C)c1C</smiles>

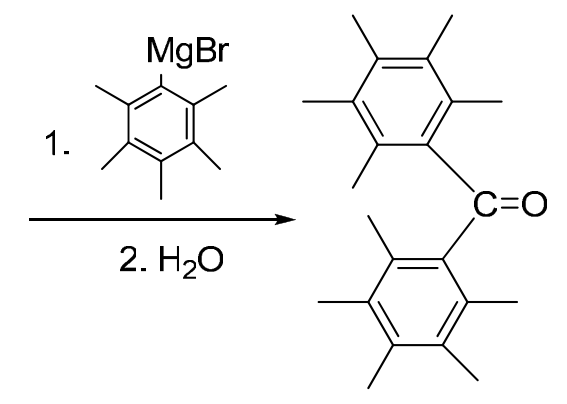

7

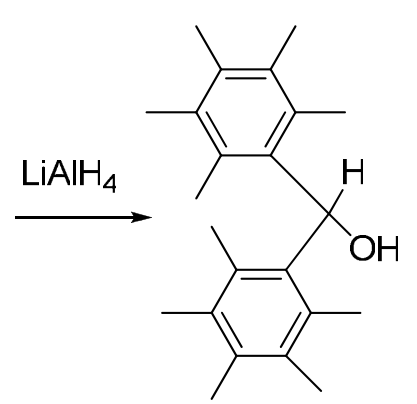

8

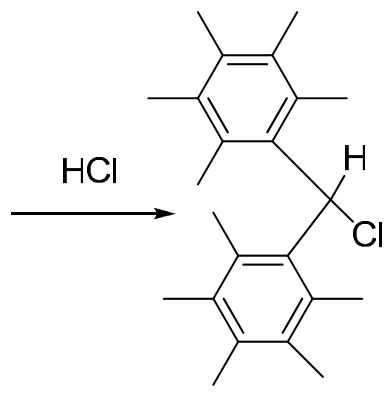

9

\section{Scheme 1}

The less hindered chlorides, chlorobis(2,4,6-trimethylphenyl)methane $\mathbf{1 2 b}$, and chlorobis(2methylphenyl)methane 12a, and the corresponding alcohols were prepared by similar sequences.

Attempts to synthesise the more sterically hindered 1,1-bis $(2,3,4,5,6-$ pentamethylphenyl)ethanol using this general approach were not successful.

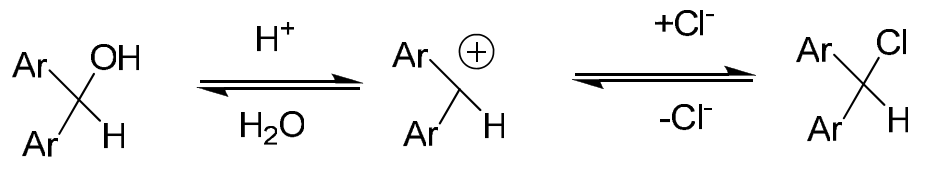

10

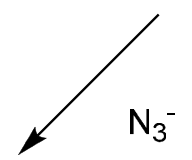

11

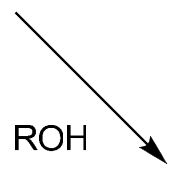

12<smiles>[R]C([Al])Br</smiles>

14

(a) $\mathrm{Ar}=2-\mathrm{MeC}_{6} \mathrm{H}_{4}$ -

(b) $\mathrm{Ar}=2,4,6-\mathrm{Me}_{3} \mathrm{C}_{6} \mathrm{H}_{2}-$

(c) $\mathrm{Ar}=2,3,4,5,6-\mathrm{Me}_{5} \mathrm{C}_{6}$

Scheme 2 
Determination of $\mathbf{p} \boldsymbol{K}_{\mathbf{R}}$ values. It has been shown that many benzhydrols ionize in $100 \%$ sulfuric acid to give stable carbocations. ${ }^{4-7}$ This ionization can be represented by Equation 1.

$$
\mathrm{Ar}_{2} \mathrm{CHOH}+2 \mathrm{H}_{2} \mathrm{SO}_{4} \rightleftharpoons \mathrm{Ar}_{2} \mathrm{CH}^{+}+2 \mathrm{HSO}_{4}^{-}+\mathrm{H}_{3} \mathrm{O}^{+}
$$

Although benzhydrol itself is unstable in sulfuric acid and undergoes rapid polymerisation and sulfonation, ${ }^{4}$ many substituted benzhydryl carbocations are sufficiently stable to permit visible absorption measurements to be undertaken.

When the three alcohols were individually dissolved in concentrated sulfuric acid, intense maxima in the visible region were observed, corresponding to the formation of the corresponding carbocation 11.
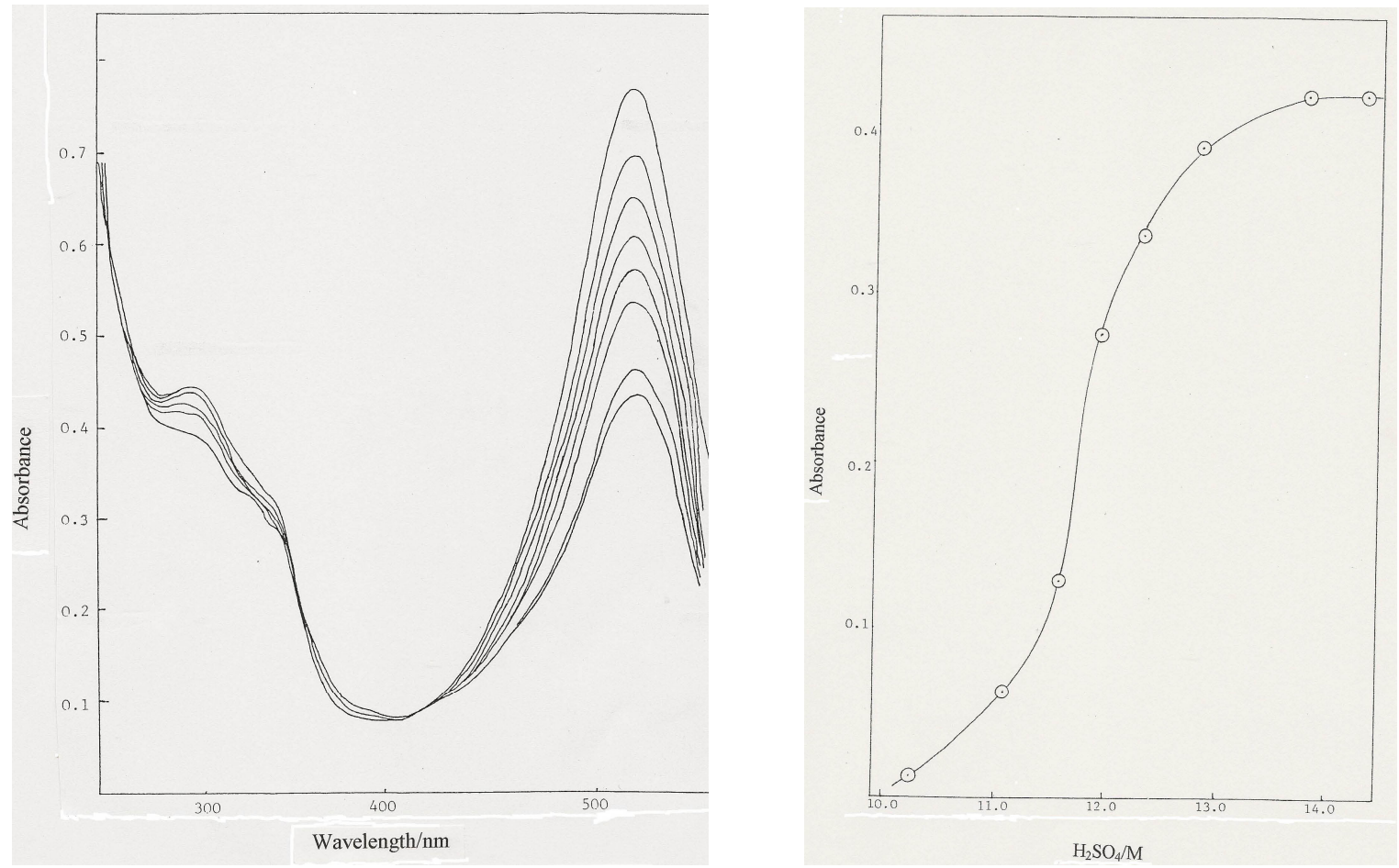

Figure 1. Repetitive scans in the ultraviolet and visible regions for the decay of the bismesitylcation $11 b$ in aqueous $\mathrm{H}_{2} \mathrm{SO}_{4}(5.0 \mathrm{M})$ at $25{ }^{\circ} \mathrm{C}$. The time interval between the scans is approximately $3 \mathrm{~min}$.

Figure 2. Plot of absorbance versus $\left[\mathrm{H}_{2} \mathrm{SO}_{4}\right]$ for $11 \mathrm{a}$ in aqueous solutions at $25{ }^{\circ} \mathrm{C}$.

Each of the carbocations is stable in the more concentrated sulfuric acid solutions, but a subsequent decay was observed in the more dilute acid solutions (see Figure 1). It has previously been shown that benzhydryl cations with two or less $o$-methyl groups form benzhydryl ethers in sulfuric acid solutions. ${ }^{7}$ However we have found that the ethers are not formed from the cations $11 \mathbf{b}$ and 11c due to the steric hindrance caused by the additional methyl 
groups. It was also found to be important to exclude oxygen in this case since the rate of the subsequent decay of the absorbance at lower acid concentration showed a small dependence on oxygen concentration. The product of the decay in the case of 11c was shown to be the corresponding bis-pentamethylphenylmethanone 7 , in the presence or absence of oxygen. We have found that the rate of decay of the absorption of 11c varied linearly with substrate concentration, and while this was not examined in detail, it suggests the presence of a second order reaction. The subsequent decay was also shown to be most significant when the cation coexists with large concentrations of the diarylmethanol.
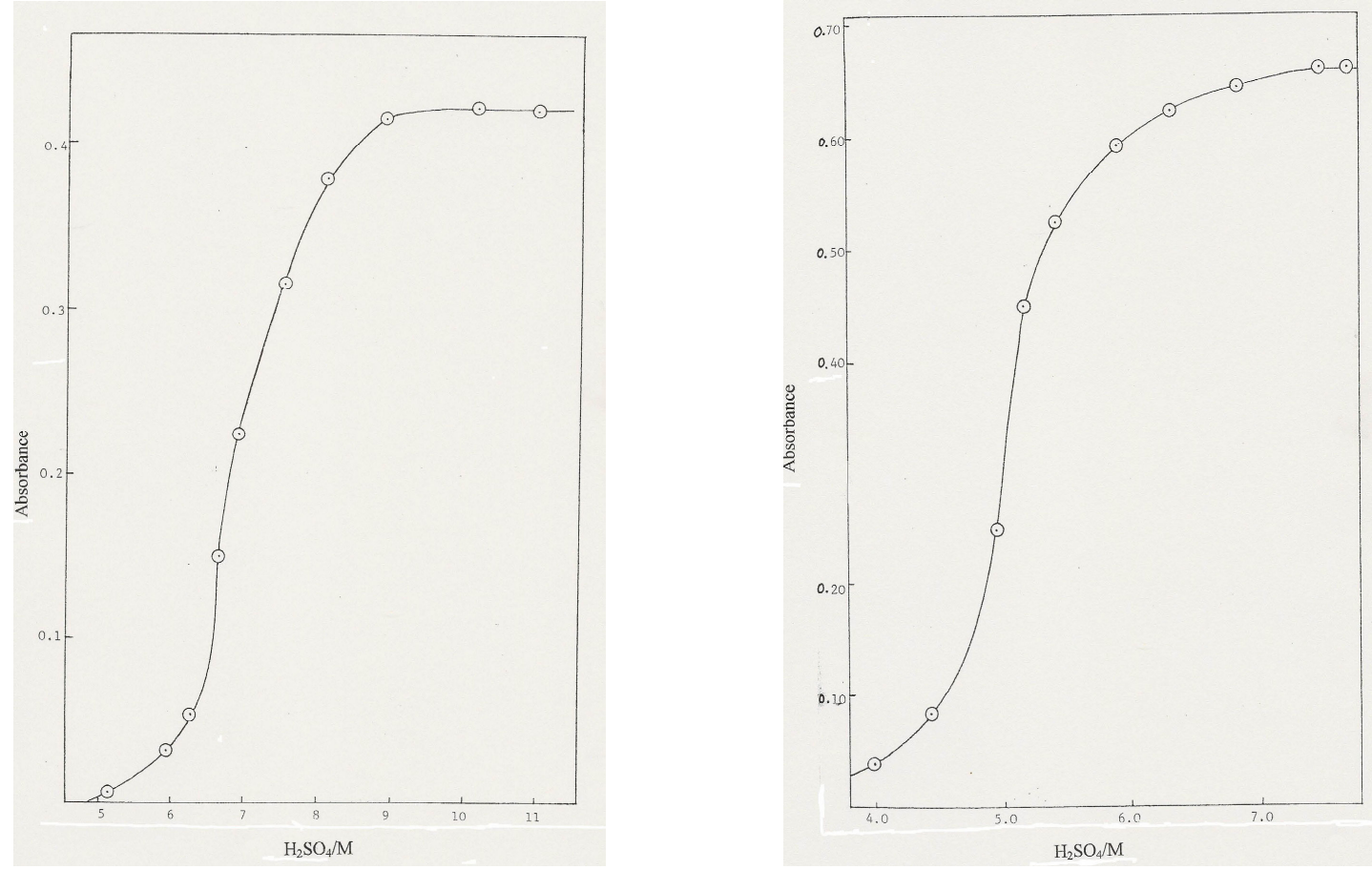

Figure 3. Plot of absorbance versus $\left[\mathrm{H}_{2} \mathrm{SO}_{4}\right]$ for $11 \mathbf{b}$ in aqueous solutions at $25^{\circ} \mathrm{C}$. Figure 4. Plot of absorbance versus $\left[\mathrm{H}_{2} \mathrm{SO}_{4}\right]$ for $11 \mathrm{c}$ in aqueous solutions at $25^{\circ} \mathrm{C}$.

A possible explanation for the formation of the ketone is shown in Equation 2, which has a precedent in the work of Bartlett. ${ }^{8}$

$$
\mathrm{Ar}_{2} \mathrm{CHOH}+\mathrm{Ar}_{2} \mathrm{CH}^{+} \longrightarrow \mathrm{Ar}_{2} \mathrm{CH}_{2}+\mathrm{Ar}_{2} \mathrm{C}=\mathrm{O}+\mathrm{H}^{+}
$$

The $\mathrm{p} K_{\mathrm{R}}$ values were therefore determined by measuring the absorptions as a function of sulfuric acid concentration and extrapolating the absorption $v$ s. time plots back to $t=0$. The subsequent reactions were minimized by using low concentrations of the substrates, so that the error in the extrapolations was minimized. 
The absorptions due to the cations $\mathbf{1 1}$ were measured at the $\lambda_{\max }$ wavelengths, which were in the visible regions in each case and extrapolation back to time of mixing gave the observed optical densities as a function of acidity (see Figures $2-4$ ).

Although the rates of decay of the absorbances showed a (small) dependence on the presence or absence of oxygen in the acid solutions, the extrapolated values were independent of the concentration of the alcohol (when corrected for concentration) and the presence or absence of oxygen.

The absorbances were plotted against acidity and the $\mathrm{H}_{\mathrm{R}}$ values ${ }^{8}$ corresponding to conversion of $50 \%$ of the alcohol to the carbocations was determined to yield the $\mathrm{p} K_{\mathrm{R}}$ values for the three carbocations studied (see Figures $2-4$ ). These are listed in Table 1, together with some relevant literature values.

Table 1. Equilibrium data obtained for substituted benzhydryl cations in sulfuric acid solutions at $25{ }^{\circ} \mathrm{C}$

\begin{tabular}{cccc}
\hline Carbocation & $\boldsymbol{\lambda}_{\max }$ & $\mathbf{p} \boldsymbol{K}_{\mathbf{R}}{ }^{\mathrm{a}}$ & $\boldsymbol{\Sigma} \boldsymbol{\sigma}^{+}$ \\
\hline$\left(\mathrm{C}_{6} \mathrm{H}_{5}\right)_{2} \mathrm{CH}^{+}$ & 440 & -13.30 & 0 \\
$\left(2-\mathrm{CH}_{3} \mathrm{C}_{6} \mathrm{H}_{4}\right)_{2} \mathrm{CH}^{+}$ & 470 & -12.69 & -0.125 \\
$\left(4-\mathrm{CH}_{3} \mathrm{C}_{6} \mathrm{H}_{4}\right)_{2} \mathrm{CH}^{+}$ & 472 & -10.40 & -0.622 \\
$\mathrm{Mes}_{2} \mathrm{CH}^{+b}$ & 528 & -6.79 & -0.922 \\
$\mathrm{PMP}_{2} \mathrm{CH}^{+\mathrm{c}}$ & 544 & -4.80 & -1.186 \\
\hline${ }^{\mathrm{a}} \mathrm{p} K_{\mathrm{R}}=-\log K_{\mathrm{R}} ;{ }^{\mathrm{b}} \mathrm{Mes}=2,4,6$-trimethylphenyl; ${ }^{\mathrm{c}} \mathrm{PMP}=2,3,4,5,6$-pentamethylphenyl
\end{tabular}

It is seen that the addition of methyl groups has a marked stabilizing effect on all of these carbocations. However two o-methyl groups have a smaller effect (by about 2 units) as compared with two $p$-methyl groups, while the two pentamethylphenyl groups significantly stabilize the cations relative to two mesityl (or 2,4,6-trimethylphenyl) groups.

The stability of a carbocation depends largely on how well the central positive ion is neutralized or distributed over the molecule by resonance, hyperconjugation and the inductive effect. While all benzhydryl cations have the capacity for resonance stabilization, the stability due to hyperconjugation increases with the increasing number of ortho and para methyl groups; the results obtained are in agreement with this. 


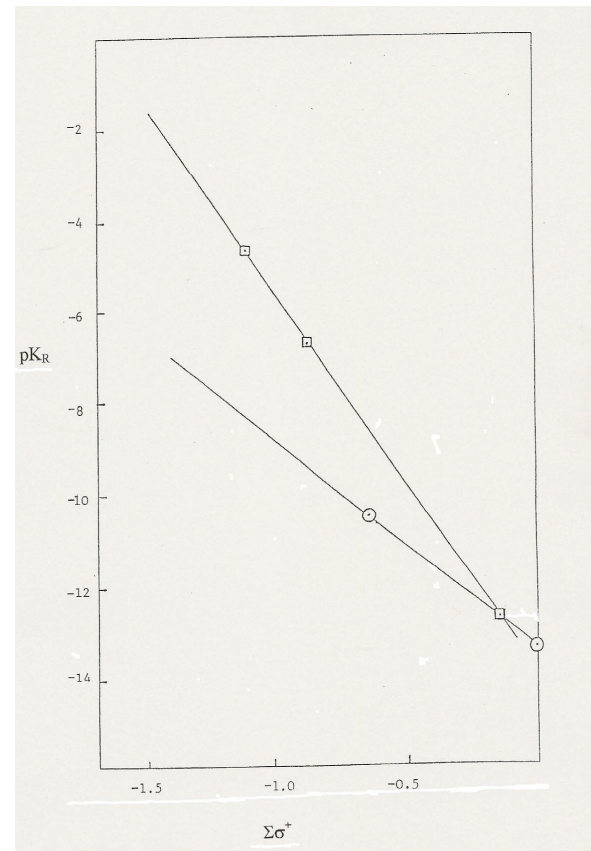

Figure 5. Plot of the sum of the sigma plus values, $\Sigma \sigma^{+}$, versus $\mathrm{p} K_{\mathrm{R}}$ values for methyl substituted benzhydryl cations; the circles represent literature data for $\mathbf{1 5}$ and $\mathbf{1 6}$, while the squares are for 11a, 11b and 11c.

It is also of interest to investigate the significance of the "buttressing effect". Newman and Deno $^{9}$ have argued that resonance in mesityldimethyl methylcarbocation is further sterically hindered by the introduction of two methyl groups in the 3- and 5-positions to form the pentamethylphenyldimethyl methylcarbocation. A similar observation might have been expected when methyl groups are introduced into the 3,5- and the 3',5'-positions in the mesityl carbocations $\mathbf{1 1 b}$, hence giving rise to greater stability of the bis-(pentamethylphenyl) cations 11c relative to the bis-mesityl cation 11b. As seen from the data in Table 1, the presence of the extra methyl groups actually stabilizes the carbocation. One might anticipate that the $\lambda_{\max }$ for the cation absorbance would be shifted to shorter wavelengths if resonance is significantly hindered by the 3,5-dimethyl substituents, but the bis-pentamethylphenyl species 11c has the longest wavelength absorbance.

A small buttressing effect in the cations is further supported when the relationship between the $\mathrm{p} K_{\mathrm{R}}$ values and the sigma values of the phenyl substituents is considered. Estimates of $\Sigma \sigma_{\text {. }}^{+}$based on arylmethanol - arylmethyl cation equilibria have been determined for substituents in the meta and para-positions, ${ }^{10-12}$ but sigma values for the ortho-positions can be complicated by steric effects. It is reasonable to expect that $\mathrm{p} K_{\mathrm{R}}$ values will be linearly related to $\sigma$ values since the difference in entropy changes for the ionization of the benzhydrols are proportional to the polar parameter $\sigma .{ }^{13}$ The relationship (two points for $\mathbf{1 5}$ and $\mathbf{1 6}$ are shown in Figure 5) between the $\mathrm{p} K_{\mathrm{R}}$ values and the sum of the $\Sigma \sigma^{+}$values for $m$ - and $p$-positions ${ }^{10-12}$ is shown in Figure 5. A substituent effect for the $o$-methyl substituent can be obtained (Figure 5) by 
extrapolation from the $\mathrm{p} K_{\mathrm{R}}$ value for (di-o-tolyl). This gives a value of -0.075 for $o$-methyl. Assuming similar magnitudes of $\sigma^{+}$for the $o$-methyl groups in the formation of the other two carbocations studied and using literature sigma values for the $p$-methyl $\left(\sigma^{+}=-0.311\right)$ and $m$ methyl group $\left(\sigma^{+}=-0.066\right)$, it is possible to plot against the corresponding $\mathrm{p} K_{\mathrm{R}}$ values, as shown in Figure 5.

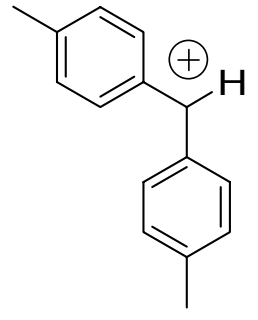

15<smiles>[C+](c1ccccc1)c1ccccc1</smiles>

16<smiles>c1ccc(C(c2ccccc2)c2ccccc2)cc1</smiles>

17

It should be noted that the slope of this line (Figure 5) is steeper for the three cations containing $o$-methyl groups (11a-11c). Thus the bis-mesityl (11b) and the bis-pentamethylphenyl cations 11c are produced from the alcohols more easily than expected from their combined substituent effects; this could be attributed to the relief of strain on carbocation formation.

Evidence for solvated carbocations in solvolysis. We have carried out a study of the rates of reaction of the chlorides $\mathbf{1 2 a}$ and $\mathbf{1 2 b}$ in $1: 1$ dioxane-water at $25{ }^{\circ} \mathrm{C}$ in the presence of various concentrations of added chloride ion. This ratio of water to dioxane was chosen both to moderate the reactivity of the chlorides 12a and $\mathbf{1 2 b}$ (which increased as the fraction of water was increased) and to ensure the solubility of the substrates. The observed rates were sensitive to the concentration of added chloride; in the case of 12a the rate decreased by a factor of 2 when the added chloride was increased from 0.024 to $0.10 \mathrm{M}$. 

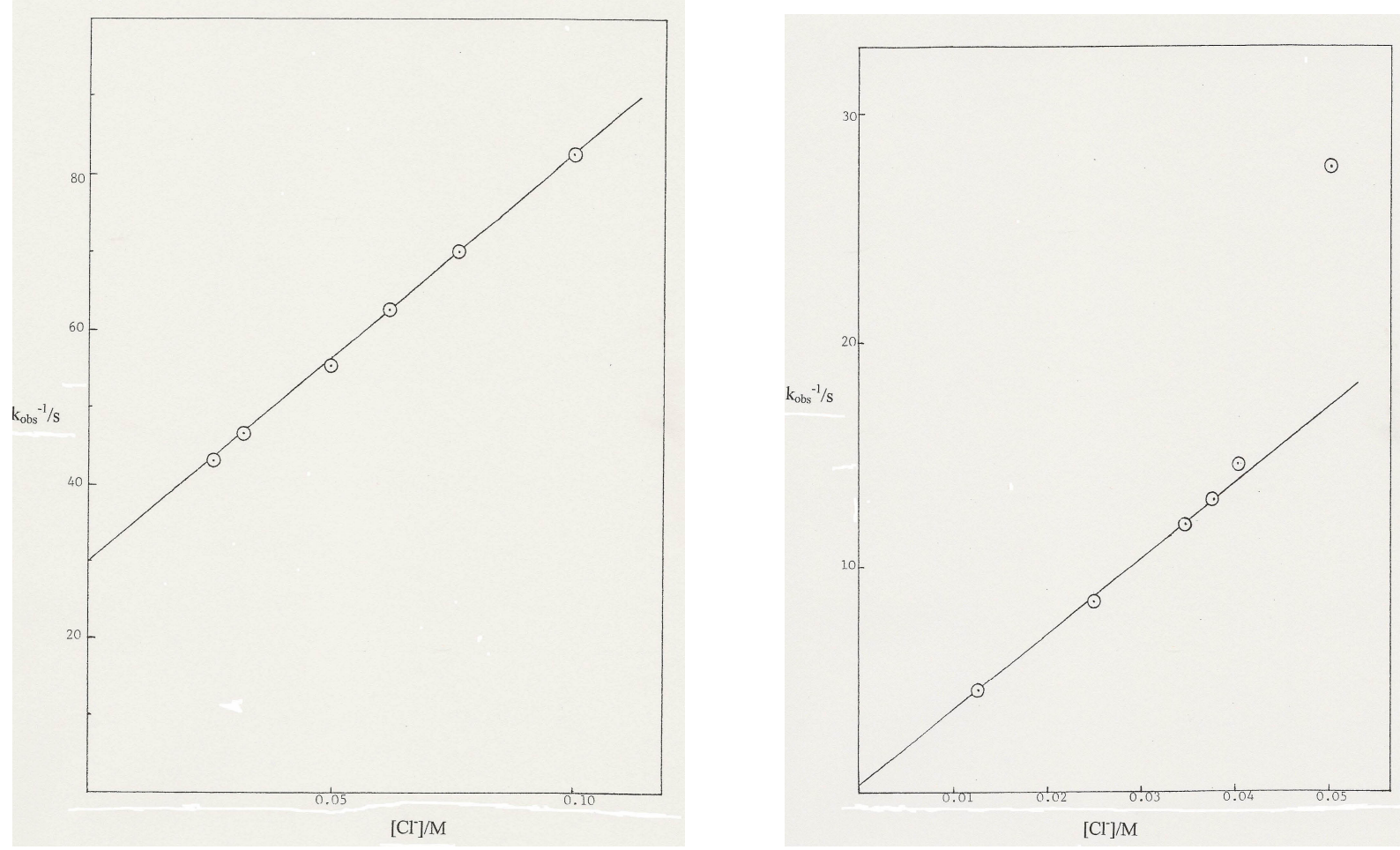

Figure 6. Plot $1 / \mathrm{k}_{\mathrm{obs}}$ versus the concentration of added chloride ion for 12a in 1:1 dioxane-water, ionic strength, $\mu=0.10\left(\mathrm{NaClO}_{4}\right)$ at $25{ }^{\circ} \mathrm{C}$; measurement of the common ion rate depression.

Figure 7. Plot $1 / \mathrm{k}_{\mathrm{obs}}$ versus concentration of added chloride ion for 12b in 85:15 dioxane-water, $\mu=0.05\left(\mathrm{NaClO}_{4}\right)$ at $25^{\circ} \mathrm{C}$; measurement of the common ion rate depression.

These results are consistent with the trapping of the free carbocation by chloride ion competing with trapping by water. More comparable selectivity values are obtained when the water content of the solvents is also taken into account. By applying Equation 3 to the systems studied, values are obtained that can be more realistically compared.

$$
\mathrm{k}_{\mathrm{Cl}-1}-\mathrm{k}_{\mathrm{H} 2 \mathrm{O}}=\alpha\left[\mathrm{H}_{2} \mathrm{O}\right]
$$

A plot of the reciprocal of the observed rate constants $\left(1 / \mathrm{k}_{\mathrm{obs}}\right)$ against $\left[\mathrm{Cl}^{-}\right]$was linear. From these data, values of $\alpha$, the mass law or selectivity constant can be calculated as 16.8 (see Figure $6)$.

The common ion rate depression was significantly larger for the more hindered $\mathbf{1 1 b}$ as substrate. For example, a 7-fold rate depression results on going from 0.0125 to $0.050 \mathrm{M}$ in added chloride ion. Again the reciprocal plot against added chloride ion was linear (Figure 7) giving a selectivity parameter (chloride ion $v s$. water) $\alpha$ of 843 . 
Table 2. Relative reactivities of chloride ion and water towards carbocations at $25{ }^{\circ} \mathrm{C}$, and the derived mass law constants, $\alpha$

\begin{tabular}{cccc}
\hline Carbocation & $\alpha$ & $\mathrm{k}_{\mathrm{Cl}}-\mathrm{k}_{\mathrm{H} 2 \mathrm{O}}$ & $\mathrm{p} K_{\mathrm{R}}$ \\
\hline$\left(\mathrm{C}_{6} \mathrm{H}_{5}\right)_{2} \mathrm{CH}^{+}$ & & 120 & -13.3 \\
$\left(2-\mathrm{CH}_{3} \mathrm{C}_{6} \mathrm{H}_{4}\right)_{2} \mathrm{CH}^{+}$ & $17^{\mathrm{a}}$ & 424 & -12.5 \\
$\left(4-\mathrm{CH}_{3} \mathrm{C}_{6} \mathrm{H}_{4}\right)_{2} \mathrm{CH}^{+}$ & $68^{\mathrm{b}}$ & $571^{\mathrm{b}}$ & -10.4 \\
$\mathrm{Mes}_{2} \mathrm{CH}^{+\mathrm{c}}$ & $843^{\mathrm{a}}$ & $7017^{\mathrm{a}}$ & -6.9 \\
$\left(\mathrm{C}_{6} \mathrm{H}_{5}\right)_{3} \mathrm{C}^{+}$ & $400^{\mathrm{d}}$ & 3311 & -6.6 \\
$\mathrm{C}_{6} \mathrm{H}_{5} \mathrm{CH}_{2}^{+}$ & $10-16$ & & \\
$2-\mathrm{MeC}_{6} \mathrm{H}_{4} \mathrm{CH}_{2}^{+}$ & $28-35$ & & \\
\hline
\end{tabular}

${ }^{\mathrm{a}}$ This work; all values were obtained in 85:15 acetone-water at $25{ }^{\circ} \mathrm{C}$, unless otherwise noted; ${ }^{\mathrm{b}}$ Measured at $0{ }^{\circ} \mathrm{C}$; ${ }^{\mathrm{c}} \mathrm{Mes}=2,4,6$-trimethylphenyl; ${ }^{\mathrm{d}}$ Measured at $0{ }^{\circ} \mathrm{C}^{14}$

These values of $\alpha$ can be compared with previously reported values for related systems (Table 2). The range of values reported in some cases results from the difficulty in producing consistent data for these sensitive compounds. Since the rate depression caused by added halide ion is associated with capture of the free carbocation by halide ion and solvent, the derived 'mass law constant' can act as a selectivity parameter, in addition to determining the extent to which the intermediate involved exists as a free cation.

Of note is the observation that the bis-mesityl cation has a higher selectivity parameter (843) than the triphenylmethyl cation 17, while these two cations have similar $\mathrm{p} K_{\mathrm{R}}$ values.

When the selectivity values, $\log \mathrm{k}_{\mathrm{Cl}}-\mathrm{k}_{\mathrm{H} 2 \mathrm{O}}$ are plotted against the corresponding $\mathrm{p} K_{\mathrm{R}}$ values (Figure 8), a linear relationship is observed for those benzhydryl cations which do not possess substituents in the ortho ring position. However, the experimentally determined selectivity values obtained for the di-o-tolyl cation 11a and the di-mesityl cation 11b lie above this line, having a greater selectivity than expected (on the basis of the data for the cations which do not carry $o$-substituents). This is consistent with the $o$-substituents providing a certain amount of protection for the cationic site, so that the rate of nucleophilic attack (by $\mathrm{Cl}^{-}$or $\mathrm{H}_{2} \mathrm{O}$ ) would be retarded relative to those cabocations which carry only $m$ - and/or $p$-substituents.

Those carbocations bearing $o$-methyl substituents (e.g. 11a - 11c) may belong to a different 'structural family', the reactivity-selectivity relationship of which may not be directly comparable to that for the para-substituted benzhydryl carbocations. A similar relatively small $(<5$-fold) increase in the rate of carbocation formation has been observed when two $o$-methyl groups are introduced into $\mathrm{XC}_{6} \mathrm{H}_{4} \mathrm{CMe}_{2} \mathrm{Y}$ (where $\mathrm{Y}$ is the leaving group, $p$-nitrobenzoate). ${ }^{2,15}$ This was attributed to the increased steric crowding at the $s p^{3}$-hybridized carbon in the ground state which is somewhat relieved in going to the transition state for cation formation.

The rates of formation of the carbocations in the absence of chloride ion can be obtained from the intercepts in Figures 6 and 7. These rates are highly dependent on the ionizing power of the solvent, as expected for reactions involving rate determining carbocation formation. While 
not studied in detail, it was observed that the rate of formation of both the bis-o-tolyl cation 11a and the bis-mesitylcarbocation 11b increase by ca. $6 \times 10^{4}$ fold in transferring from 85:15 dioxane-water to 1:1 dioxane water.

The bis-pentamethylphenylchloromethane 12c behaved differently under these conditions and, as a result, the common-ion rate depression was not measured for this chloride. An absorbance appeared at $320 \mathrm{~nm}$ which we have assigned to competing formation of the elimination product, the xylylene $\mathbf{3}$ (see below).

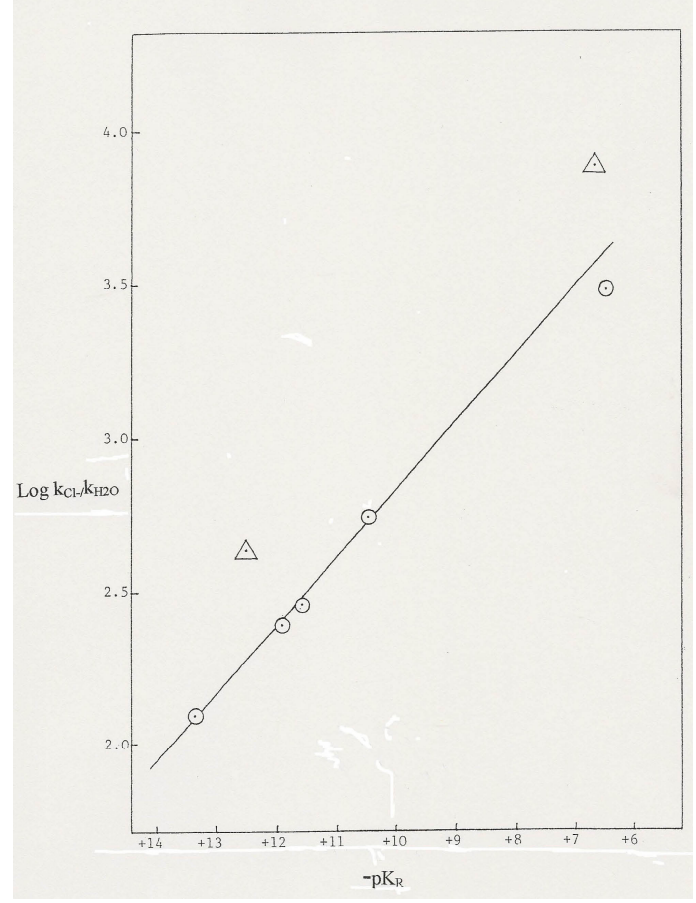

Figure 8. Plot $\log \mathrm{k}_{\mathrm{Cl}}-\mathrm{k}_{\mathrm{H} 2 \mathrm{O}}$ versus $\mathrm{p} K_{\mathrm{R}}$ for substituted diarylmethylcations in $85: 15$ acetonewater at $25^{\circ} \mathrm{C}$; the circles are literature data values and the triangles are from this work (11a and 11b).

Azide-water competition. Azide ion is known to react rapidly with carbocations, usually at a diffusion controlled rate and has therefore been used, in competition reactions, to estimate the absolute rates of reaction of various cations. We have therefore examined a series of competition reactions between various concentrations of added azide ion in mixed acetone-water solutions. Product analysis was carried out using HPLC, following isolation, or by using the (small) differences in the methane hydrogen in ${ }^{1} \mathrm{H}$ NMR.

In order to avoid possible problems due to mixing and the build up of the carbocations in localized areas, different water concentrations were used in each case; these water concentrations were chosen so that the half life for the formation of the carbocations was significantly longer than the mixing time. 

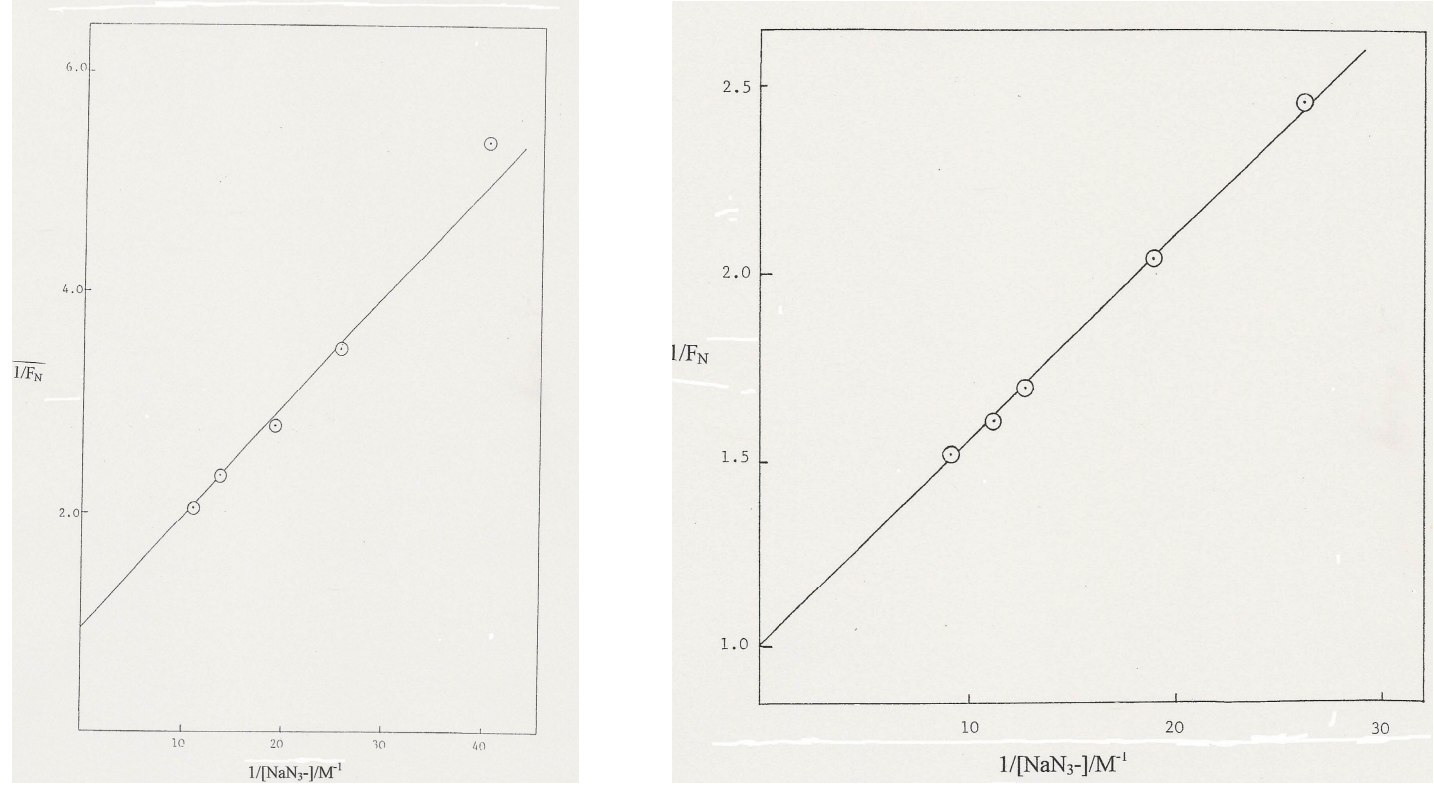

Figure 9. Plot of $1 / \mathrm{F}_{\mathrm{N}}$ versus $1 /\left[\mathrm{N}_{3}{ }^{-}\right]$for 11a in $2: 1$ acetone-water $\mu=0.10\left(\mathrm{NaClO}_{4}\right)$ at $25^{\circ} \mathrm{C}$. Figure 10. Plot of $1 / \mathrm{F}_{\mathrm{N}}$ versus $1 /\left[\mathrm{N}_{3}^{-}\right]$for $\mathbf{1 1 b}$ in $85: 15$ acetone-water $\mu=0.10\left(\mathrm{NaClO}_{4}\right)$ at $25^{\circ} \mathrm{C}$.
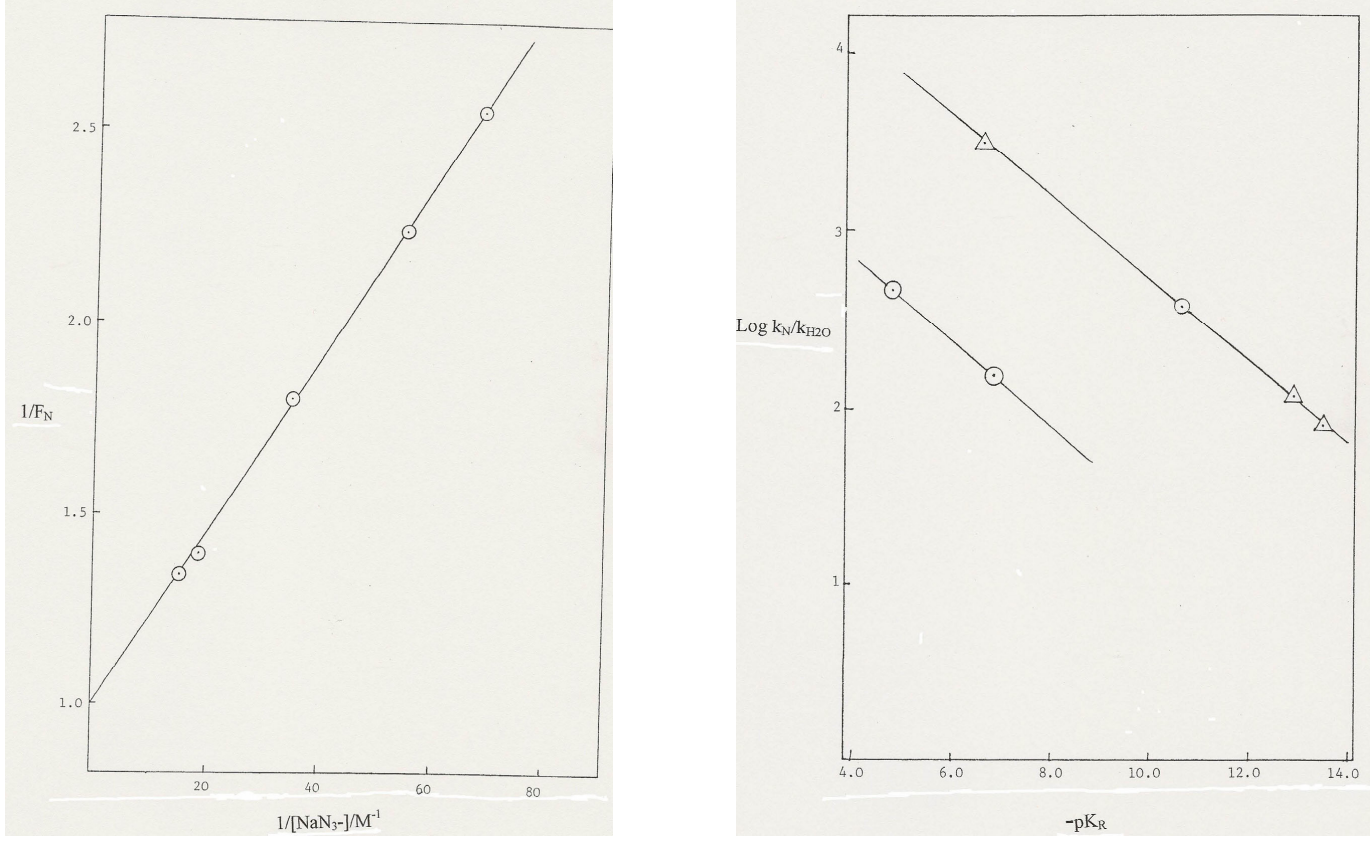

Figure 11. Plot of $1 / \mathrm{F}_{\mathrm{N}}$ versus $1 /\left[\mathrm{N}_{3}{ }^{-}\right]$for $11 \mathrm{c}$ in $80: 20$ acetone-water $\mu=0.20\left(\mathrm{NaClO}_{4}\right)$ at $25^{\circ} \mathrm{C}$ Figure 12. Plot of $\log \left(\mathrm{k}_{\mathrm{N} 3}{ }^{-} / \mathrm{k}_{\mathrm{H} 2 \mathrm{O}}\right)$ versus $-\mathrm{p} K_{\mathrm{R}}$ for substituted benzhydryl cations in 80:20 acetone-water at $25{ }^{\circ} \mathrm{C}$; the triangles are from literature data and the circles are from this work.

The fraction of the carbocation trapped by azide ion $\left(\mathrm{F}_{\mathrm{N}}\right)$ was then determined, relative to the total amount of cation trapped by the competing reagents (water and azide ion). Double 
reciprocal plots of $1 / \mathrm{F}_{\mathrm{N}}$ against the inverse of the concentration $\left(1 /\left[\mathrm{N}_{3}{ }^{-}\right]\right.$were linear in each case (Figure $9-11$ ). The values were corrected for the different concentrations of water used to yield the $\mathrm{k}_{\mathrm{N} 3} / \mathrm{k}_{\mathrm{H} 2 \mathrm{O}}$ values which are listed in Table 3.

Table 3. Relative rate constants, $\mathrm{k}_{\mathrm{N} 3}-\mathrm{k}_{\mathrm{H} 2 \mathrm{O}}$, for the reaction of alkyl chlorides in 80:20 acetonewater at $25{ }^{\circ} \mathrm{C}$

\begin{tabular}{cc}
\hline Substrate & $\mathrm{k}_{\mathrm{N} 3}-/ \mathrm{k}_{\mathrm{H} 2 \mathrm{O}}$ \\
\hline$\left(4-\mathrm{MeOC}_{6} \mathrm{H}_{4}\right)_{3} \mathrm{CCl}$ & $2.04 \times 10^{7}$ \\
$\left(4-\mathrm{MeC}_{6} \mathrm{H}_{4}\right)_{2} \mathrm{CHCl}$ & $291-716$ \\
$\left(\mathrm{Me}_{5} \mathrm{C}_{6}\right)_{2} \mathrm{CHCl} \mathrm{12c}$ & 483 \\
$\left(2,4,6-\mathrm{Me}_{3} \mathrm{C}_{6} \mathrm{H}_{2}\right)_{2} \mathrm{CHCl}^{\mathrm{a}}$ & 151 \\
$\mathbf{1 2 b}$ & 192 \\
$\left(2-\mathrm{MeC}_{6} \mathrm{H}_{4}\right)_{2} \mathrm{CHCl}^{\mathrm{b}}$ & \\
\hline${ }^{\mathrm{a}} 85: 15$ acetone-water; $^{\mathrm{b}} 3: 2$ acetone-water.
\end{tabular}

The good linearity observed and the low concentrations of azide ion which we have used would tend to indicate that there was not a major contribution of general base catalysis of water attack on the carbocation by azide ion. ${ }^{16}$

The intermediate that reacts with water and azide ion might be either a carbocation-leaving group ion pair that is formed in an irreversible step or the free (solvated) carbocation. The results presented earlier for the common ion rate depression on the addition of chloride ion favour a mechanism involving trapping of a solvent equilibrated carbocation. Richard and Jencks ${ }^{17}$ have provided convincing evidence to show that, although a free carbocation is the reacting species, the rate constants for the reactions of azide ion can be diffusion controlled.

Combining a value of $5 \times 10^{9} \mathrm{M}^{-1} \mathrm{~s}^{-1}$ for $\mathrm{k}_{\mathrm{N} 3}$ - with the experimentally determined values of $\mathrm{k}_{\mathrm{N} 3}$ $/ \mathrm{k}_{\mathrm{H} 2 \mathrm{O}}$ enabled the rate constants for the reaction of water with a series of substituted 1phenylethyl carbocations to be evaluated. ${ }^{18,19}$ The $\mathrm{k}_{\mathrm{N} 3}-/ \mathrm{k}_{\mathrm{H} 2 \mathrm{O}}$ values for these compounds ranged from $7.7 \times 10^{7}$ for the 1-(4-dimethylaminophenyl)ethyl carbocation to a value of 0.71 for 1 -(3methoxyphenyl)ethyl derivative. Diffusion controlled trapping by azide ion (the 'azide clock' reaction) has since been widely used to estimate absolute second order rate constants for a number of systems and to understand systems where there are changes in reactivity-selectivity behaviour. These values can be related to the corresponding equilibrium stabilities, as measured by the $\mathrm{p} K_{\mathrm{R}}$ values (Figure 12 ).

A very marked difference in selectivities is not observed for the benzhydryl cations studied (see Table 3). A more significant range might be anticipated, based on the relative ease of formation of the cations and the differences in $\mathrm{p} K_{\mathrm{R}}$ values, but the rates of water attack on the carbocations are activation (rather than diffusion) controlled. 
Reaction of carbocations 11 with alcohols. The relative reactivities of stable and highly reactive carbocations towards nucleophilic reagents has been examined directly in some detail, ${ }^{3 \mathrm{c}}$ but studies with more reactive carbocations have been limited because of mixing problems. We have studied the reactivity of our three carbocations towards a number of substituted alcohols and water. The carbocations were generated from the corresponding chloromethane derivatives 12 and the relative rates of reaction were estimated from product analysis.

The bis(pentamethylphenyl) carbocation 11c shows a large selectivity in its reaction with different alcohols. This is illustrated by the reactivity ratios of 72 for methanol, 46 for ethanol and 30 for 2-methoxyethanol relative to isopropanol (Table 4). This contrasts with the much smaller range observed with the bis-mesityl carbocation 11b (Table 4). The difference in reactivity between the secondary alcohol, isopropanol, and the primary alcohols studied can again be ascribed largely to steric effects, and this is most obvious when there are five methyl groups in both aryl rings.

The reaction rate of the carbocations with water is unusually low; for example it is 45 times less reactive than methanol for the most stable carbocation 11c, but only 1.7 fold less reactive for the bis-mesityl analogue 11b. This type of behaviour (low reactivity of water) however does have precedent in the reactions of 1 -arylethyl carbocations. ${ }^{20}$ In effect, water is behaving as an alcohol of $\mathrm{pK}_{\mathrm{a}}$ about 13. It is suggested that this behaviour might arise from the larger polarisability and intrinsic electron donating power of the alcohols compared with water.

Table 4. Relative rate constants for reaction of alcohols with diarylchloromethanes 12 at $25{ }^{\circ} \mathrm{C}$; (relative to the reaction with isopropanol)

\begin{tabular}{ccc}
\hline Alcohol &.$\left(\mathrm{Me}_{5} \mathrm{C}_{6}\right)_{2} \mathrm{CHCl}$ & $\left(2,4,6-\mathrm{Me}_{3} \mathrm{C}_{6} \mathrm{H}_{2}\right)_{2} \mathrm{CHCl}$ \\
& $12 \mathrm{c}$ & $12 \mathrm{~b}$ \\
\hline Methanol & 71.6 & 2.64 \\
Ethanol & 46.2 & 0.89 \\
2-Methoxyethanol & 30.0 & \\
Trifluoroethanol & 1.88 & 1.59 \\
Water & 1.60 & 1.00 \\
Isopropanol & 1.00 & \\
\hline
\end{tabular}

Formation of elimination product, 5,6-dimethylenecyclohexa-1,3-diene 3. Initial attempts to measure the common ion effect for the bis-pentamethylphenyl substrate 12c were hampered by the formation of a new product, characterized by the appearance of an absorption at $320 \mathrm{~nm}$. This is clearly not the formation of the carbocation 11c, which was observed in sulfuric acid solution and has a very minor absorption at $320 \mathrm{~nm}$. The $320 \mathrm{~nm}$ absorption is also observed when 12c is added (in a dilute solution) to dioxane (see Figure 13), but not when it is added to benzene. However when triethylamine (a base) is added to benzene, the $320 \mathrm{~nm}$ absorption is formed and does not vary in intensity as extra base is added. 
The ${ }^{1} \mathrm{H}$ NMR spectrum of the product formed in benzene, following the removal of triethylamine hydrochloride, showed two vinylic singlets at $\delta 5.22$ and $\delta 7.20 ;{ }^{13} \mathrm{C}$ data confirms this assignment. These observations are consistent with a 'xylylene' $\mathbf{3}$ structure for the species giving rise to the $320 \mathrm{~nm}$ absorption. In a separate experiment $\mathbf{3}$ was also trapped by reaction (1,4-addition) by bromine.
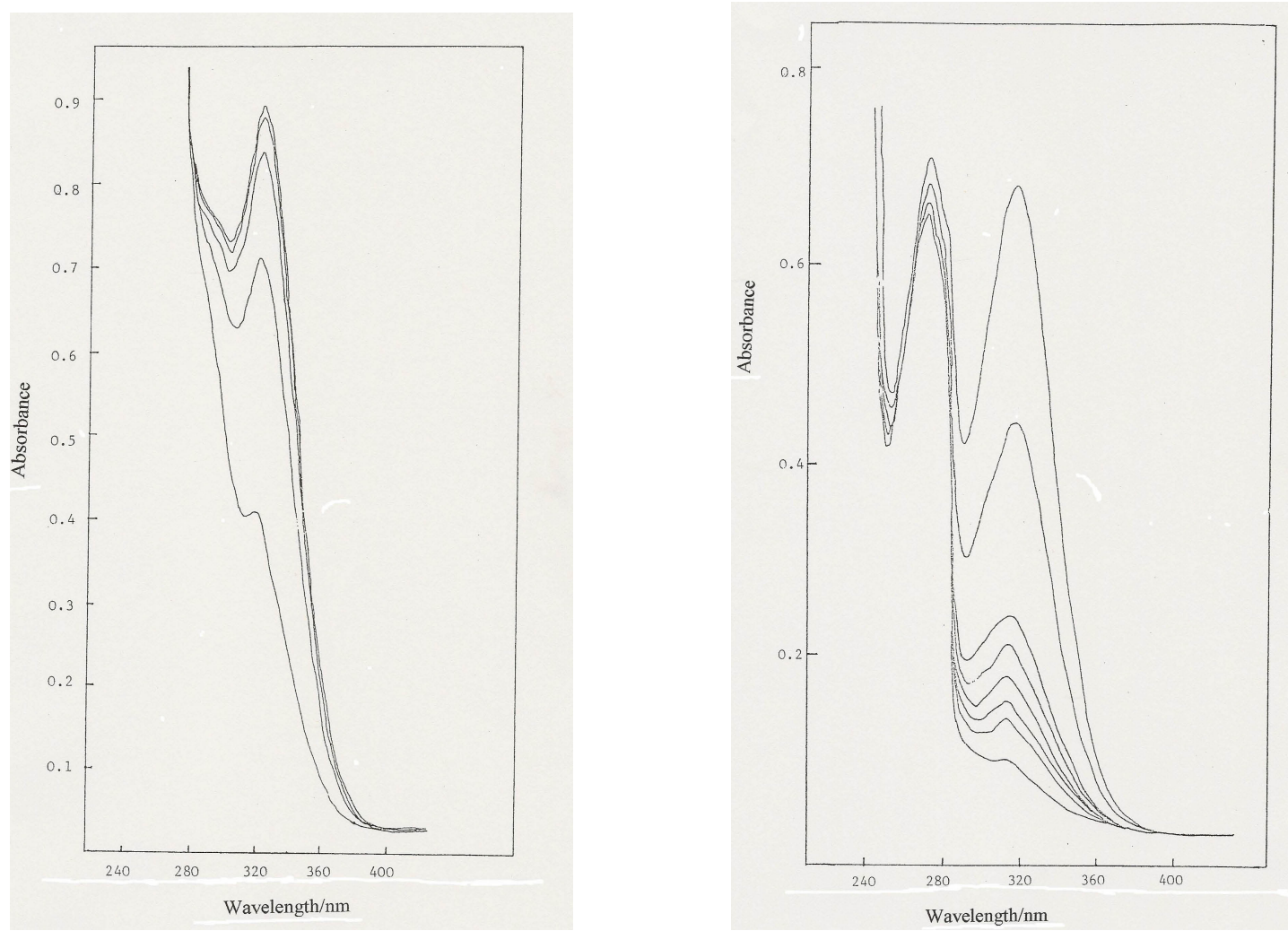

Figure 13. Repetitive scans of the uv/vis region for the formation of $\mathbf{3}$ in dioxane at $25{ }^{\circ} \mathrm{C}$. The time interval between scans is $1.5 \mathrm{~min}$.

Figure 14. Repetitive scans for the decay of $\mathbf{3}$ in $93: 7$ dioxane-water at $25{ }^{\circ} \mathrm{C}$. The time between scans is $2 \mathrm{~min}$.

While the formation of $\mathbf{3}$ is observed in dioxane and not in the poorer ionizing solvent benzene (in the absence of added base), the rate of formation in dioxane is greatly accelerated in water-dioxane mixtures suggesting that the rate determining step for the formation of $\mathbf{3}$ is the formation of the carbocation 11c, which then reacts with chloride ion (in dioxane) or with water to give the deprotonation product $\mathbf{3}$. The $320 \mathrm{~nm}$ absorption subsequently decays in these waterdioxane solvents (see Figure 14), to give the alcohol 12c as the final product. Note that the xylylene 3 was still formed at quite high water concentrations, but the percentage formed decreased and there was an observed decrease in the subsequent rate of decay of the $320 \mathrm{~nm}$ 
absorption. This is consistent with competing deprotonation and water attack on the most hindered carbocation 11c studied.

Measurable xylylene formation was not detected (using the sensitive $u v$ analysis) for either of the other bis-arylchloromethanes 12a, 12b, used as substrates in mixed organic-water solvents.

Carbocation pKa determination. The subsequent reaction of the xylylene 3 to give the corresponding alcohol 10c is acid catalysed. This reaction was followed at $320 \mathrm{~nm}$ where $\mathbf{3}$ had an absorption maximum. A plot of the observed rate against the concentration of added $\mathrm{HCl}$ in 1:1 dioxane-water gave a value of $\mathrm{k}_{\mathrm{h}}$ of $0.424 \mathrm{M}^{-1} \mathrm{~s}^{-1}$ The ratio of the first order rate constants for the hydration and dehydration steps can be determined by a method analogous to that used by Schubert and Keefe. ${ }^{21}$ The stoichiometric ratio of alcohol to xylylene to alcohol was determined at $320 \mathrm{~nm}$ in the $\mathrm{pH}$ range $4.6-5.8$; the ratio was independent of $\mathrm{pH}$ under these conditions and the rate of protonation of the xylylene was relatively slow. This gives $\mathrm{k}_{\mathrm{H} 2 \mathrm{O}}=22 \mathrm{k}_{\mathrm{d}}$; deprotonation by water is therefore much slower than nucleophilic attack (hydration) of the cation, consistent with protonation being rate limiting in the xylylene hydration.

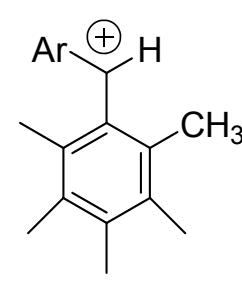

18

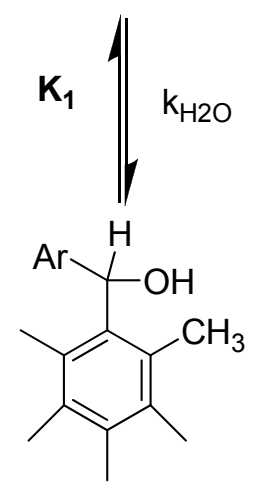

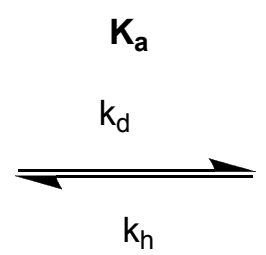

19<smiles></smiles>

\section{Scheme 4}

The acid dissociation constant for the bis-pentamethylphenyl cation 11c to form the xylylene 3 (Scheme 4) can be derived from the ratio of the rate constants $k_{d} / k_{h}$. Using the value of $k_{H 2 O}$ of $1.03 \times 10^{7} \mathrm{M}^{-1} \mathrm{~s}^{-1}$ determined earlier, this gives an estimated $\mathrm{K}_{\mathrm{a}}$ of $1.1 \times 10^{6}$ (or $\mathrm{pK}_{\mathrm{a}}$ of -6.04 ) for the carbocation (see Scheme 4). 
It is interesting to compare the ease of proton abstraction from the 1-(4-methylphenyl)ethyl cation 21 with the bis-pentamethylphenyl analogue, 18 (or 11c). The presence of the intervening phenyl group significantly increases the stability of the carbocation; $K_{1}$ for $11 \mathrm{c}$ is eight orders of magnitude larger than for 21 where $\mathrm{K}_{1}$ is $1.7 \times 10^{-13} \mathrm{M}^{-1}{ }^{22}$ In the reverse direction, the proximity of the methyl group in $\mathbf{2 1}$ to the cationic site presumably enhances proton abstraction, due to rapid neutralization of the positive charge on removal of the proton.

Partitioning of cumyl cations 22 depends on the solvent (and trapping agent) used and the presence (22b) or absence (22a) of $o$-methyl substituents. Creary ${ }^{23}$ has shown that almost exclusive deprotonation occurs at the indicated site in $\mathbf{2 2 b}$ to yield the corresponding alkene, although later work has demonstrated that trapping of this sterically hindered cation can also be observed under a variety of conditions. ${ }^{2}$

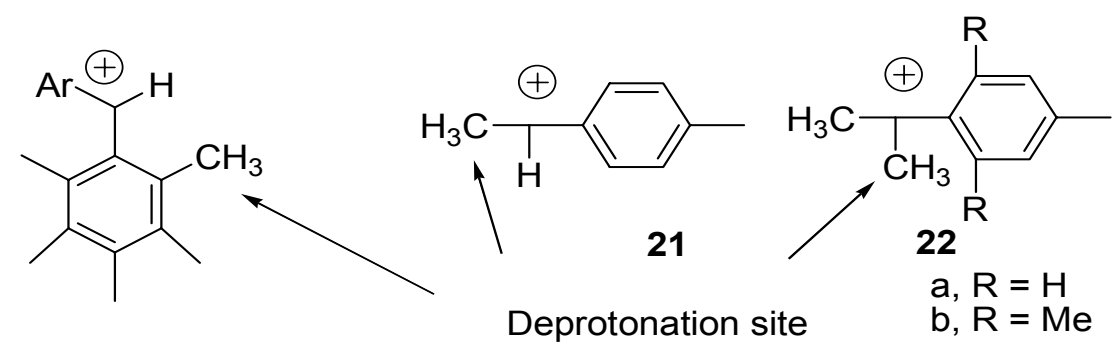

\section{Conclusions}

We have demonstrated that the bis-pentamethylphenyl carbocation 11c is significantly more stable, relative to the corresponding alcohols, than the bis-mesityl 11b or bis-o-tolyl 11a carbocations as shown by the trend in $\mathrm{p} K_{\mathrm{R}}$ values. The $o$-methyl groups have a relatively small effect on carbocation stability, probably since they induce non-planarity, reducing the degree of stabilization of the carbocation centre.

Large differences in the ratios of attack on the three carbocations by nucleophiles $\mathrm{H}_{2} \mathrm{O}, \mathrm{Cl}^{-}$ and alcohols studied were found, with the greatest selectivity being found with 11c for reactions with secondary alcohols.

Competing elimination with water attack was observed, but only with the carbocation 11c. This led to the formation of the xylylene $\mathbf{3}$, which was identified spectroscopically in solution and by trapping with bromine. In the presence of acid, $\mathbf{3}$ underwent rate determining protonation at a measurable rate, which allowed an estimation of a $\mathrm{pK}_{\mathrm{a}}$ for the carbocation.

While deprotonation is able to compete with direct water attack on these carbocations only when the two aromatic rings carry pentamethylphenyl groups (as opposed to o-tolyl or mesityl groups), this may not be solely due to the greater steric hindrance to water attack in the case of 
11c. Another contributing factor may be the thermodynamic stabilization of the diene $\mathbf{3}$ formed by the extra two methyl groups.

\section{Experimental Section}

General Procedures. Melting points were taken on a Mel-Temp capillary apparatus and are uncorrected with respect to stem correction. ${ }^{1} \mathrm{H}$ and ${ }^{13} \mathrm{C}$ NMR spectra were recorded on a $400 \mathrm{MHz}$ Bruker ADVANCE DRX-400 Multinuclear NMR spectrometer. Chemical shifts are reported in reference to TMS as internal standard. IR spectra were recorded on a Perkin-Elmer 881 Spectrometer $\left(v\right.$ in $\left.\mathrm{cm}^{-1}\right)$. Elemental analyses were obtained from SMU Analytical Service Laboratories. HPLC analysis were carried out on a Waters Delta prep 4000 instrument equipped with a Whelk-01 (25 cm x 4.6) column (purchased from Regis Technologies, Inc.) and UV detector at $254 \mathrm{~nm}$. The eluent, hexane/isopropanol $(70 / 30, \mathrm{v} / \mathrm{v})$ was run at flow rate of $1 \mathrm{~mL} / \mathrm{min}$. GC/MS was performed on HP 7673 Automatic Sampler Instrument.

Azide ion competition reaction solutions were prepared using acetone-water mixtures as solvent with varying concentrations of sodium azide (ionic strength was maintained constant by the addition of $\mathrm{NaClO}_{4}$ ). Reactions were initiated by the addition of the substrate to a fixed volume of the reaction solution to give a usual final concentration in the range $0.007-0.0015 \mathrm{M}$ but without the addition of a buffer. Reactions were stirred at $25^{\circ}$ for $30 \mathrm{~min}$, after which time the solvent was evaporated under reduced pressure. The organic components were then isolated for analysis. The organic components of the sold residue were dissolved in a small volume of HPLC grade methanol and filtered. Aliquots were then injected directly onto a Waters Radial Compression Module and eluted with $\mathrm{MeOH}-\mathrm{H}_{2} \mathrm{O}$ mixtures. Detection was carried out at fixed wavelength $(214 \mathrm{~nm})$ and integration of the peaks. Comparison of the retention times with those of authentic samples, prepared separately, was carried out in all cases, and concentrations were determined by examining authentic samples at the same wavelengths.

For the alcohol trapping competitive reactions, stock solutions were prepared using $80 \%(\mathrm{v} / \mathrm{v})$ dioxane and 20\% combined nucleophilic reagents (alcohols). The alcohols were distilled before use, except for trifluoroethanol, which was Aldrich Gold Label grade. Water was doubly distilled from an all-glass apparatus. Isopropanol was used in all of the solutions and its concentration was varied relative to the competing alcohol. The reactions were initiated by the addition of a fixed volume of a stock solution of the alkyl halide to give a final substrate concentration of $7.3 \mathrm{mM}$. Each mixture was then stirred at $25{ }^{\circ} \mathrm{C}$ to complete reaction before the solvent was removed under reduced pressure. Product ratios were then determined by ${ }^{1} \mathrm{H}$ NMR, principally using the methine proton for analysis in $\mathrm{CDCl}_{3}$ solutions.

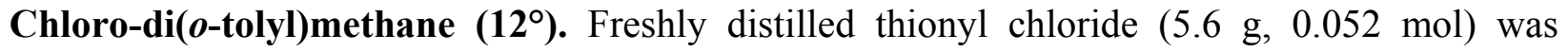
added to a solution of di-o-tolylmethanol $(10.0 \mathrm{~g}, 0.047 \mathrm{~mol})$ in dried carbon tetrachloride $(100 \mathrm{~mL})$. After refluxing for $2 \mathrm{~h}$, the solvent was removed under reduced pressure to give a 
buff coloured solid which was recrystallised from petroleum spirits $\left(40-60{ }^{\circ} \mathrm{C}\right) \mathrm{mp} 69.8-70.5{ }^{\circ} \mathrm{C}$ (10.84 g, 98\%). ${ }^{1} \mathrm{H}$ NMR $\left(\mathrm{CDCl}_{3}\right): \delta 2.35(\mathrm{~s}, 6 \mathrm{H}), 6.62(\mathrm{~s}, 1 \mathrm{H}), 7.45(\mathrm{~m}, 8 \mathrm{H})$. Anal. Calcd for $\mathrm{C}_{15} \mathrm{H}_{15} \mathrm{Cl}$ : C,78.08; H, 6.55; Cl, 15.36\%. Found: C,78.02; H, 6.44; Cl, 15.64\%.

Azido di-o-tolylmethane (13a). Sodium azide (2.60g; $0.04 \mathrm{~mol})$ and trichloroacetic acid (40 g) were stirred in chloroform $(20 \mathrm{~mL})$ at room temperature for $15 \mathrm{~min}$. At $30{ }^{\circ} \mathrm{C}$ a suspension of di$o$-tolylmethanol $(4.25 \mathrm{~g}, 0.02 \mathrm{~mol})$ in chloroform $(20 \mathrm{~mL})$ was added over $30 \mathrm{~min}$. Following stirring for a further $2 \mathrm{~h}$, the mixture was poured onto ice $(200 \mathrm{~g})$. The organic layer was washed with aqueous sodium bicarbonate, and then with water. After drying $\left(\mathrm{MgSO}_{4}\right)$, the solvent was evaporated. Recrystallisation of the crude product from petroleum spirits $\left(60-80{ }^{\circ} \mathrm{C}\right)$ gave the azide $(4.27 \mathrm{~g}, 90 \%)$ as buff coloured prisms, mp $140.5-141.1{ }^{\circ} \mathrm{C} .{ }^{1} \mathrm{H}$ NMR: $\delta 2.28(\mathrm{~s}, 6 \mathrm{H}) ; 6.00$ $(\mathrm{s}, 1 \mathrm{H}) ; 7.25(\mathrm{~m}, 8 \mathrm{H})$. IR: $v\left(\mathrm{C}-\mathrm{N}_{3}\right) 2177 \mathrm{~cm}^{-1}$. Anal. Calcd for $\mathrm{C}_{15} \mathrm{H}_{15} \mathrm{~N}_{3}$ : C, 75.92; H, 6.37; N,17.71\%. Found: C,75.54; H, 6.39; N, 17.54\%.

Azidodimesitylmethane (13b) was similarly prepared in $80 \%$ yield and had $\mathrm{mp} 88.7-89.5^{\circ} \mathrm{C}$. ${ }^{1} \mathrm{H}$ NMR: $\delta 2.19(\mathrm{~s}, 12 \mathrm{H}) ; \delta 2.24(\mathrm{~s}, 6 \mathrm{H}) ; v 6.08(\mathrm{~s}, 1 \mathrm{H}) ; \delta 6.76(\mathrm{~s}, 4 \mathrm{H})$. IR $v\left(\mathrm{C}-\mathrm{N}_{3}\right) 2091 \mathrm{~cm}^{-1}$. Anal. Calcd for $\mathrm{C}_{19} \mathrm{H}_{23} \mathrm{~N}_{3}$ : C, 77.78; H, 7.90; N, 14.32\%. Found: C, 77.78; H, 8.18; N, 14.33\%. Azidobis(2,3,4,5,6-pentamethylphenyl)methane (13c) was similarly prepared from the corresponding alcohol except that the reaction mixture was stirred overnight at $35{ }^{\circ} \mathrm{C}$. The product was a white solid obtained in $85 \%$ yield with mp 140.5 -141.4 ${ }^{\circ} \mathrm{C}$. ${ }^{1} \mathrm{H}$ NMR: $\delta 2.28$ (s, $1 \mathrm{H}) ; 2.32$ (s, 12H); 6.58 (s, 1H). IR: v. $\left(\mathrm{C}-\mathrm{N}_{3}\right) 2096 \mathrm{~cm}^{-1}$. Anal. Calcd. for $\mathrm{C}_{23} \mathrm{H}_{31} \mathrm{~N}_{3}$ : C, 79.04; H, 8.94; N, 12.02\%. Found: C, 80.17; H, 9.32; N,11.86\%.

Bis(2,3,4,5,6-pentamethylphenyl)methanone (7). To a solution of aluminum trichloride (54.06 g, $0.406 \mathrm{~mol})$ in $\mathrm{CS}_{2}(120 \mathrm{~mL})$ at $10^{\circ} \mathrm{C}$ was added oxalyl chloride (32 mL, $\left.0.406 \mathrm{~mol}\right)$. A solution of pentamethylbenzene $(60.0 \mathrm{~g}, 0.406 \mathrm{~mol})$ in $\mathrm{CS}_{2}(80 \mathrm{ml})$ was added over $1 \mathrm{~h}$ with the temperature being maintained at $10{ }^{\circ} \mathrm{C}$. The solution was then allowed to stir overnight at room temperature. The resulting red-brown slurry was then poured cautiously onto ice $(500 \mathrm{~g})$. The water layer was separated and the organic layer was washed twice with water $(2 \times 500 \mathrm{~mL})$ and then washed twice with a solution of $\mathrm{KOH}\left(30 \mathrm{~g}\right.$ in $\left.500 \mathrm{~mL} \mathrm{H}_{2} \mathrm{O}\right)$. The aqueous layers were combined and acidified to $\mathrm{pH} 1$ with concentrated $\mathrm{HCl}$. The precipitated pentamethylbenzoic acid was filtered, washed well with $\mathrm{H}_{2} \mathrm{O}$ and dried thoroughly in an oven.

Pentamethylbenzoic acid (30 g, $0.156 \mathrm{~mol})$ was allowed to stand overnight with excess thionyl chloride $(50 \mathrm{~mL})$ when the excess was removed under reduced pressure. Any remaining thionyl chloride was removed by the addition of benzene $(50 \mathrm{~mL})$ and evaporation of the solvent, a process that was repeated three times. The acid chloride was dissolved in dry THF (50 mL) and slowly added to a Grignard solution prepared from bromopentamethylbenzene ${ }^{24}$ (35.46 g, $0.156 \mathrm{~mol})$ and $\mathrm{Mg}(7.29 \mathrm{~g}, 0.312 \mathrm{~mol})$ in dry $\mathrm{THF}$ at $0{ }^{\circ} \mathrm{C}$. The reaction was vigorous and reached reflux to give an intense purple solution. The solution was allowed to cool to room temperature before the addition of dilute $\mathrm{HCl}$. The precipitated ketone was filtered off, washed well with water and recrystallised from toluene. It was then recovered as a white powder, $\mathrm{mp}$ $208.5-210.0{ }^{\circ} \mathrm{C}(34.21 \mathrm{~g}, 68 \%) .{ }^{1} \mathrm{H}$ NMR: $\delta 2.16(\mathrm{~s}, 6 \mathrm{H}) ; 2.26(\mathrm{~s}, 6 \mathrm{H}) ; 2.34$ (s,3H). IR: $y$ $(\mathrm{C}=\mathrm{O}) 1645 \mathrm{~cm}^{-1}$ Anal. Calcd. For $\mathrm{C}_{23} \mathrm{H}_{30} \mathrm{O}$ : C, 85.66; H, 9.38\%. Found: 85.71 ; H, 9.43\%. 
Bis(2,3,4,5,6-pentamethylphenyl)methanol (10c). Bis(2,3,4,5,6-pentamethylphenyl)methanone (10.0 g, $0.031 \mathrm{~mol})$ was added over $15 \mathrm{~min}$ to a suspension of $\mathrm{LiAlH}_{4}(1.77 \mathrm{~g}, 0.046 \mathrm{~mol})$ in dry tetrahydrofuran $(70 \mathrm{~mL})$. The solution was refluxed for $1 \mathrm{~h}$ and then cooled to $0{ }^{\circ} \mathrm{C}$. It was slowly poured into excess ethyl acetate $(100 \mathrm{~mL})$ and the entire solution was then added to dilute $\mathrm{HCl}$. The organic layer was separated and the aqueous phase extracted twice with ether. Evaporation of the dried $\left(\mathrm{MgSO}_{4}\right)$ organic layer gave the pure alcohol as white needles $(9.04 \mathrm{~g}$, 90\%), mp $193.5-194.2{ }^{\circ} \mathrm{C} .{ }^{1} \mathrm{H}$ NMR: $\delta 1.80(\mathrm{~d}, 1 \mathrm{H}) ; 2.20(\mathrm{~s}, 2.20) ; 2.27(\mathrm{~s}, 18 \mathrm{H}) ; 6.59(\mathrm{~d}$, 1H). IR: v (C-O) $1386 \mathrm{~cm}^{-1}$; (O-H) $1456 \mathrm{~cm}^{-1}$; $v(\mathrm{O}-\mathrm{H}) 3335 \mathrm{~cm}^{-1}$. Anal. Calcd for $\mathrm{C}_{23} \mathrm{H}_{32} \mathrm{O}: \mathrm{C}$, 85.13; H, 9.94\%. Found: C, 85.53; H, 10.16\%.

Chloro-bis(2,3,4,5,6-pentamethylphenyl)methane (12c). Sodium sulfate (40.9 g, $0.31 \mathrm{~mol})$ was added to a solution of bis(2,3,4,5,6-pentamethylphenyl)methanol (20 g, $0.062 \mathrm{~mol})$ in dry benzene $(100 \mathrm{~mL})$ and dry $\mathrm{HCl}$ gas was bubbled through the solution for $1 \mathrm{~h}$. The solution was filtered and the benzene removed under reduced pressure. Recrystallisation from petroleum spirits $\left(40-60{ }^{\circ} \mathrm{C}\right)$ gave the product as lilac crystals $(19.1 \mathrm{~g}, 90 \%), \mathrm{mp} 121.6-122.5{ }^{\circ} \mathrm{C} .{ }^{1} \mathrm{H}$ NMR $\delta 2.20(\mathrm{~s}, 12 \mathrm{H}) ; 2.27(\mathrm{~s}, 18 \mathrm{H}) ; 7.40(\mathrm{~s}, 1 \mathrm{H})$. IR $v(\mathrm{C}-\mathrm{Cl}) 705 \mathrm{~cm}^{-1}$. Anal. Calcd for $\mathrm{C}_{23} \mathrm{H}_{31} \mathrm{Cl}: \mathrm{C}, 80.55 ; \mathrm{H}, 9.11 ; \mathrm{Cl}, 10.34 \%$. Found: C, 80.75; H, 9.01; Cl, 10.14\%.

2,4,6-Trimethylbenzoic acid was prepared by a literature method from 1-bromo-2,4,6trimenthylbenzene ${ }^{25}$ and was isolated in $56 \%$ yield and had $\mathrm{mp} 147-148{ }^{\circ} \mathrm{C}$ (lit., ${ }^{25} \mathrm{mp} 146-$ $\left.147{ }^{\circ} \mathrm{C}\right)$. The corresponding acid chloride was prepared in $97 \%$ yield by stirring the acid chloride with thionyl chloride and distilling the product at $143-146^{\circ} \mathrm{C} / 60 \mathrm{~mm} .^{25}$

Bis(2,4,6-trimethylphenyl)methanone was prepared in $75 \%$ yield using a literature procedure and had mp $138-139{ }^{\circ} \mathrm{C}$ (lit., ${ }^{26} \mathrm{mp} 138-139^{\circ}$ ). This was reduced to the corresponding alcohol using $\mathrm{LiAlH}_{4}$; the alcohol was isolated as white needles, mp $149-150{ }^{\circ} \mathrm{C}\left(\right.$ lit., $\left.{ }^{26}\right) 149-150{ }^{\circ} \mathrm{C}$.

Chloro-bis(2,4,6-trimethylphenyl)methane (12b) was prepared from the alcohol 10b $(4.0 \mathrm{~g}$, $0.015 \mathrm{~mol})$ which was dissolved in dry $\mathrm{CCl}_{4}$ and thionyl chloride $(1.16 \mathrm{~mL}, 0.016 \mathrm{~mol})$ and refluxed for $2 \mathrm{~h}$. The solid obtained on evaporation of the solvent was recrystallised from petroleum spirits $\left(40-60{ }^{\circ} \mathrm{C}\right)$ to give an off-white powder, mp $104-105{ }^{\circ} \mathrm{C}$ (lit., ${ }^{27} \mathrm{mp} 104-$ $\left.105^{\circ} \mathrm{C}\right)$.

Reaction of chloro-bis-(2,3,4,5,6-pentamethylphenyl)methane (12c) with base and then with bromine. The chloromethane $(1.0 \mathrm{~g}, 0.003 \mathrm{~mol})$ was allowed to stand with pyridine $(0.25 \mathrm{~mL}$, $0.003 \mathrm{~mol}$ ) in dry benzene at ambient temperature for $20 \mathrm{~min}$. The solution was then cooled to $3{ }^{\circ} \mathrm{C}$ to complete the precipitation of the pyridine hydrochloride salt which was filtered off. The solution was then maintained at $3{ }^{\circ} \mathrm{C}$ during the addition of bromine $(0.30 \mathrm{~g}, 0.003 \mathrm{~mol})$. The reaction with bromine was rapid and after $15 \mathrm{~min}$ the benzene solvent was evaporated under reduced pressure. Attempted recrystallisation from methanol led to decomposition, but it was successfully recrystallised from hexane to yield a white solid (1.40 g, 95\%) identified as 1pentamethylphenyl-1-(2',3',4',5'-tetramethyl-6'-bromomethylphenyl)bromomethane. The MS gave a molecular ion signal at 466 , corresponding to the dibromo derivative and signals were also observed at 385 and 305, corresponding to the loss of one and two HBr. ${ }^{1} \mathrm{H}$ NMR: $\delta 2.20$, 
$2.24,2.26,2.30$ in the ratio of $2: 1: 2: 1$ respectively; $\delta 4.61(\mathrm{~s}, 2 \mathrm{H}) ; 7.25(\mathrm{~s}, 1 \mathrm{H}) .{ }^{13} \mathrm{C} \mathrm{NMR}: \delta$ $56.30(\mathrm{CH}-\mathrm{Br}) ; 31.30,31.16\left(\mathrm{CH}_{2}-\mathrm{Br}\right)$. Anal. Calcd for $\mathrm{C}_{23} \mathrm{H}_{30} \mathrm{Br}_{2}: \mathrm{C}, 59.24 ; \mathrm{H}, 6.49 ; \mathrm{Br}$, $34.27 \%$. Found: C, 59.32; H, 6.64; Br, 34.43\%. Attempts were also made to trap 3 with acrylonitrile, but these were unsuccessful, probably due to steric hindrance at the diene site.

\section{Acknowledgements}

We acknowledge the award of an Enterprise Ireland Basic Science Scholarship to V.E.W. and are grateful to Rory More O'Ferrall for many helpful discussions.

\section{References and Notes}

1. Allen, B. M.; Hegarty, A. F.; O’Neill, P. J. Chem. Soc., Perkin Trans. 2 1997, 2733.

2. Aymes, T. L.; Mizerski, T.; Richard, J. P. Can. J. Chem. 1999, 77, 922.

3. For recent reviews on carbocation reactivity, see (a) Richard, J. P.; Amyes, T.L.; Lin, S.; O’Donoghue, A. C.; Toteva, M. M.; Tsuji, Y.; Williams, K. B. Adv. Phys. Org. Chem., 2000, 35, 67; (b) Richard, J. P.; Amyes, T. L.; Toteva, M. M.; Tsuji, Y. Adv. Phys. Org. Chem., 2004, 39, 1; (c) Mayr, H.; Ofinal, A. R. Pure Appl. Chem. 2005, 77, 1807.

4. Welch, C. M.; Smith, H. A. J. Am. Chem. Soc. 1950, 72, 4748.

5. Newman, M. S.; Deno, N. C. J. Am. Chem. Soc. 1951, 73, 3644.

6. Gold. V.; Tye, F. L. J. Chem. Soc. 1952, 2172.

7. (a) Smith, H. A.; Thompson, R. G. J. Am. Chem. Soc. 1955, 77, 1778. (b) Smith, H. A.; Stewart, B. B. J. Am. Chem. Soc. 1957, 79, 3693.

8. Bartlett, P. R. Carbonium ions - An introduction, Academic Press: New York, 1967.

9. Newman, M. S.; Deno, N. C. J. Am. Chem. Soc. 1951, 73, 3650

10. Bartlett, P. R. ; McCollum, P. D. J. Am. Chem. Soc. 1956, 78, 1441.

11. Bateman, L. C.; Church, M. G.; Hughes, E. O.; Ingold, C. K.; Taher, N. A. J. Chem. Soc. 1940, 979.

12. Deno, N. C.; Evans, W. L. J. Am. Chem. Soc. 1957, 79, 5804.

13. Deno, N. C.; Jaruzelski, J. J.; Schriesheim, A. J. Am. Chem. Soc. 1954, 77, 3044.

14. Bailey, T. H.; Fox, J. R.; Jackson, J.; Kohnstam, G.; Queen, A. J. Chem. Soc. Chem. Commun. 1966, 122.

15. Richard, J. P.; Lin, S.; Buccigross, J. M.; Amyes, T. L. J. Am. Chem. Soc. 1996, 118 , 12603.

16. Bateman, L. C.; Hughes, E. D.; Ingold, C. K. J. Chem. Soc. 1940, 974.

17. Richard, J. P.; Rothenberg, M. E.; Jencks, W. P. J. Am. Chem. Soc. 1984, 106, 3693.

18. Young, P. R.; Jencks, W. P. J. Am. Chem. Soc. 1977, 99, 8238. 
19. McClelland, R. A.; Cozens, F. L.; Steenken, S.; Amyes, T. L.; Richard, J. P. J. Chem. Soc., Perkin Trans 2. 1993, 1717.

20. Richard, J. P.; Jencks, W. P. J. Am. Chem. Soc. 1979, 101, 3288.

21. Schubert, W. M.; Keefe, J. R. J. Am. Chem. Soc. 1972, 94, 559.

22. Richard, J. P.; Jencks, W. P. J. Am. Chem. Soc. 1984, 106, 1373.

23. Creary, X.; Casingal, V. P.; Leahy, C.E. J. Am. Chem. Soc. 1993, 115, 1734.

24. Clement, H. Ann. Chim. 1940, 13, 343.

25. Smith, L .I. Org. Synth. Coll. 1946, 2, 95.

26. Barnes, R. P. Org. Synth. Coll. 1955, 3, 555.

27. Nauta, W. T. Recl. Trav. Chim. 1937, 56, 535. 